\title{
Lessons learnt - The role of peer-to-peer lecture films in a first year material science laboratory course
}

\section{Anja Pfennig}

HTW Berlin, Universtiy of Applied Sciences HTW Berlin, Germany.

\begin{abstract}
At HTW Berlin material science is taught to first year students in combination with laboratory exercises on materials testing. Still, basic knowledge upon theory is necessary to work practically during lab sessions. Therefore homework reading is assigned and additionally lecture films guide students through the laboratory routine prior to class. Initially inspired by students these lecture films were conducted during a one term student semester project according to the peer-to-peer approach supervised by lecturers and film experts. Since establishing the lecture films in summer semester 2015 time consuming explanations were redundant and the students were prepared better gaining more knowledge during practical work than those who did not have access to the films. After watching the introductory films download activities increased and online lectures were prepared carefully. However, the initial increase in final test results is not valid taken into account all grades from 2015 up to now. Still, even if the academic output is not better with our without the implementation of lecture films, the better handling of laboratory equipment and the more smoothly running lab courses account for at least a part time success.
\end{abstract}

Keywords: lecture films, inverted classroom, peer to peer, material science, laboratory. 


\section{Introduction and peer-to-peer laboratory videos}

Material Science is taught to first year mechanical engineering students at HTW Berlin via the "design-led" teaching approach: Ashby (2013), Pfennig (2016-1/2), Pfennig (2018) first facing the engineering product, then introducing its properties and later relating these to microstructure, atomistic structure and progressing to the physics and chemistry of materials. Teaching goal is the understanding of material science, but moreover to educate students and prepare them for their role as a maker of things (Ashby 2013).

Students enroll into HTW applied university come from multiple different educational backgrounds, which is a benefit and a great challenge at the same time. It is necessary to study the scientific background of material properties to understand the material test results gained in the lab course. The concept follows a blended learning scenario where scientific backgrounds are self-studied via online-lectures. Discussions are encouraged, but each student is responsible for her/his own progresseion. Therefore a great variety of teaching material is provided via moodle: Pfennig (2016-2), Pfennig (2018).

In the blended learning setting implementing lecture videos into "inverted classroom" teaching scenarios: Berret (2012), Pfennig (2016-2), Pfennig (2018), Pfennig (2019-2) has a positive effect on self-efficacy beliefs and intrinsic motivation Thai (2017). Note, that there is a difference between audio or video recordings of lectures comprising at least 5 different techniques: Crooka (2017) and short lecture videos of relevant course material: Pfennig (2016-1). In general students rate lecture videos as easy to use and effective learning tools: Kay (2012) and place significant value on the use of videos: Gulley (2016), Kon (2015). Videos provide an audio and visual stimulus covering different learning methodologies. Presupposed the video included is analogous to the desired learning outcomes of the lecture: Al-Jandan (2015) lecture videos are definitely a reinforcement, rather than a replacement for lectures: Havergal (2015). Interpolated questions within online videos were preferred by students and may increase the learner's engagement with the material: Rose (2016) and help to boost actual performance: Szpunar (2014).

Involving students directly into teaching activities (preparation of lecture videos) engage studets in critical thinking: Colorado State University (2015), thus, producing deeper learning outcomes: Goto and Schneider (2010). As "peer-to-peer": Ware (2015) literally means "from students for students" this concept was applied for planning and completing lecture videos at HTW Berlin according to the 3I-model: Pfennig (2016-1/2), Pfennig (2018) (figure 1). Effective operation of the lecture films is based on students`experience and their special needs when preparing for specific topics in material science. Therefore 4-6 students worked on a full concept and implementation and integration of three to six lecture films, each two to eight minutes long. The film making was supervised by the lecturer and director of photography of the HTW: Pfennig (2016-1/2), Pfennig (2019-1). 


\section{inform, instruct, give impulse.}

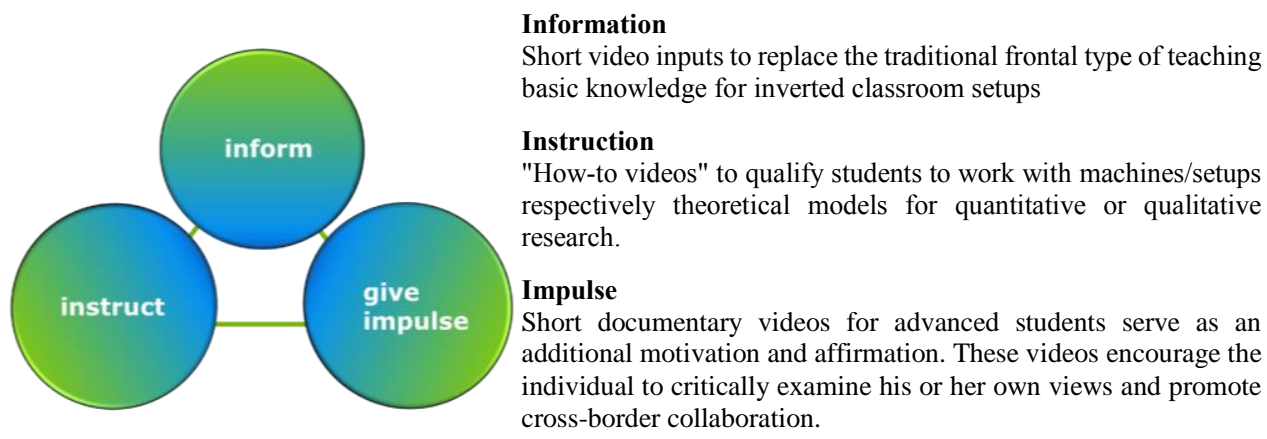

Fig. 1. 3I Model Overview: Pfennig (2018).

5 "how-to" motion picture lecture videos (11:42 $\mathrm{min})$ on materials testing and introduction to the laboratory course as well as 7 animated scientific lecture videos: Pfennig (2019-1/2) were produced to make the materials science laboratory come to life. These are integrated into micro lectures on Moodle and various teaching material: Pfennig (2018) (figure 2):

\begin{tabular}{|l|l|l|}
\hline $\begin{array}{l}\text { Laboratory } \\
\text { introduction }\end{array}$ & $\begin{array}{l}\text { Heat treatment } \\
(3: 08 \mathrm{~min})\end{array}$ \\
$\mathbf{5}$ films /11:42 & $\begin{array}{l}\text { Ultrasonic testing } \\
(1: 22 \mathrm{~min})\end{array}$ \\
Mow to video & $\begin{array}{l}\text { Microstructure } \\
(1: 44 \text { min }) \\
\text { Tensile strength testing } \\
(1: 19 \text { min }) \\
\text { Hardness } \\
(3: 09 \text { min })\end{array}$
\end{tabular}

Fig. 2.5 "how-to" motion picture lecture videos (11:42 $\mathrm{min})$ on materials testing and introduction to the laboratory course. Scientific lecture films are not openly available yet.

The material science laboratory course basically addresses first year students in mechanical engineering, economical engineering, and automotive engineering. In general students did not find it appealing to pick suiting lectures and study properly on their own when preparing for the lab course. Hence, most lab courses were very challenging, a lot of time was consumed by repeated explanations making the lab course disappointing for lecturers. The joy of handson courses could not be felt: Pfennig (2016-1). This research now provides broader test results and a first resume on the efficiency of "how-to" lecture videos in a first year material science laboratory course. 


\section{Course results}

The concept of implementing lecture films prior to the laboratory course applied first in spring semester: Pfennig (2016-1) and overall results slightly increased (grade average in WS2014/15: 1,92 (64 students) compared to SS2015: 1,87 (84 students). Lower grades in WS2015 $(1,99)$ are due to large differences of the results obtained from mechanical engineering $(1,80)$ and automotive engineering students $(2,17)$. In SS $2016(1,58)$ and SS $2017(1,50)$ grades were better than all previous semesters counting for both, students of mechanical and automotive engineering. Winter semester 2016/17 $(1,86)$ and spring semester $2018(1,83)$ and $2019(1,96)$ showed a good average for all experiments. Winter semester 2017/18 and 2018/19 displayed the worst results since data collection. Here, the special situation of german higher education has to be taken into account with refugees entering the system. Students with migration background of these particular semester showed severe lack of language skills and therefore averagely scored significantly lower. With semesters of 65\% of the students coming from Maghreb countries even lecture video supported laboratory courses did not deliver sufficiently satisfying results. It might also be possible that the outstanding results of the mechanical engineering students in winter semester 2014/15 raised the grade point average of this semester so that the results obtained by the following semesters are comparedly better than figure 3 shows.

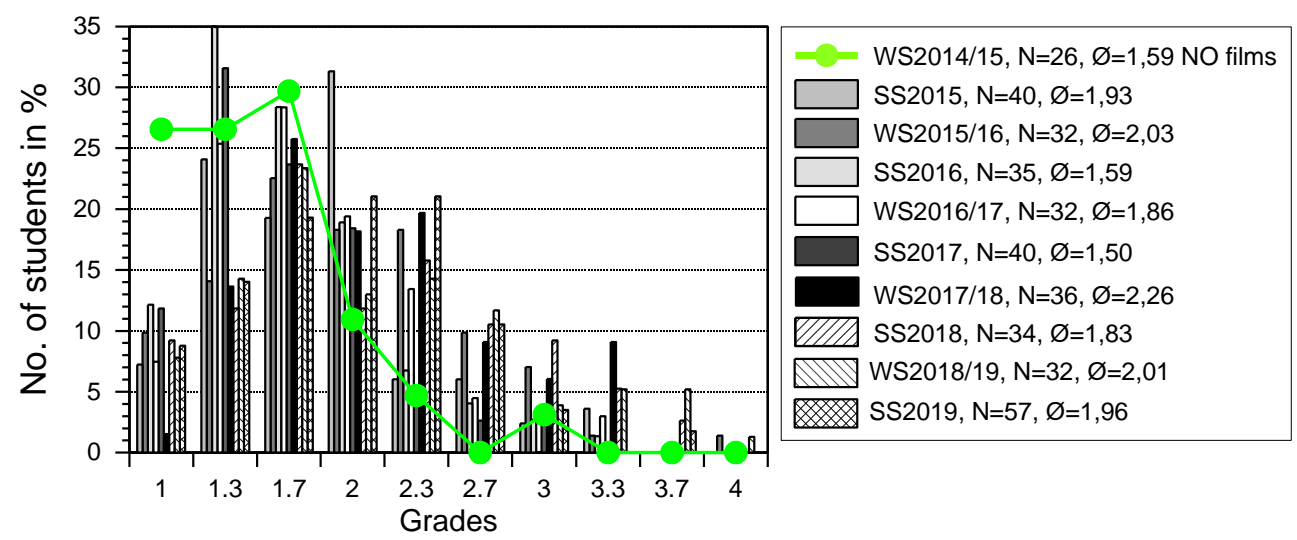

Fig. 3. Accumulated grades for 5 different experiments of students taking a lab course at HTW comparing fall semester 2014 without lecture films (green line) and all semesters from spring semester 2015 until spring semester 2019 with lecture films (histogram).

Considering every experiment of the laboratory course separately, a slight shift towards better grades after watching and working with lecture films was noticeable for the most difficult themes: ultrasonic testing and microstructural analysis. Still, there is no significant increase in grades. Although there is a shift towards lower grades since establishing lecture films as means of self-taught learning prior to laboratory classes, the number of students failing the class is very low (figure 3 ). 


\section{Evaluation and Discussion}

Because lecture films appeal to many students, are easily accessible, repeatable and time and locally independent (figure 4) the combination of watching the films and preparing online lectures are prefered by most students. YouTube statistics show that once the students started to watch the films they completed at least $75 \%$ (figure 4).

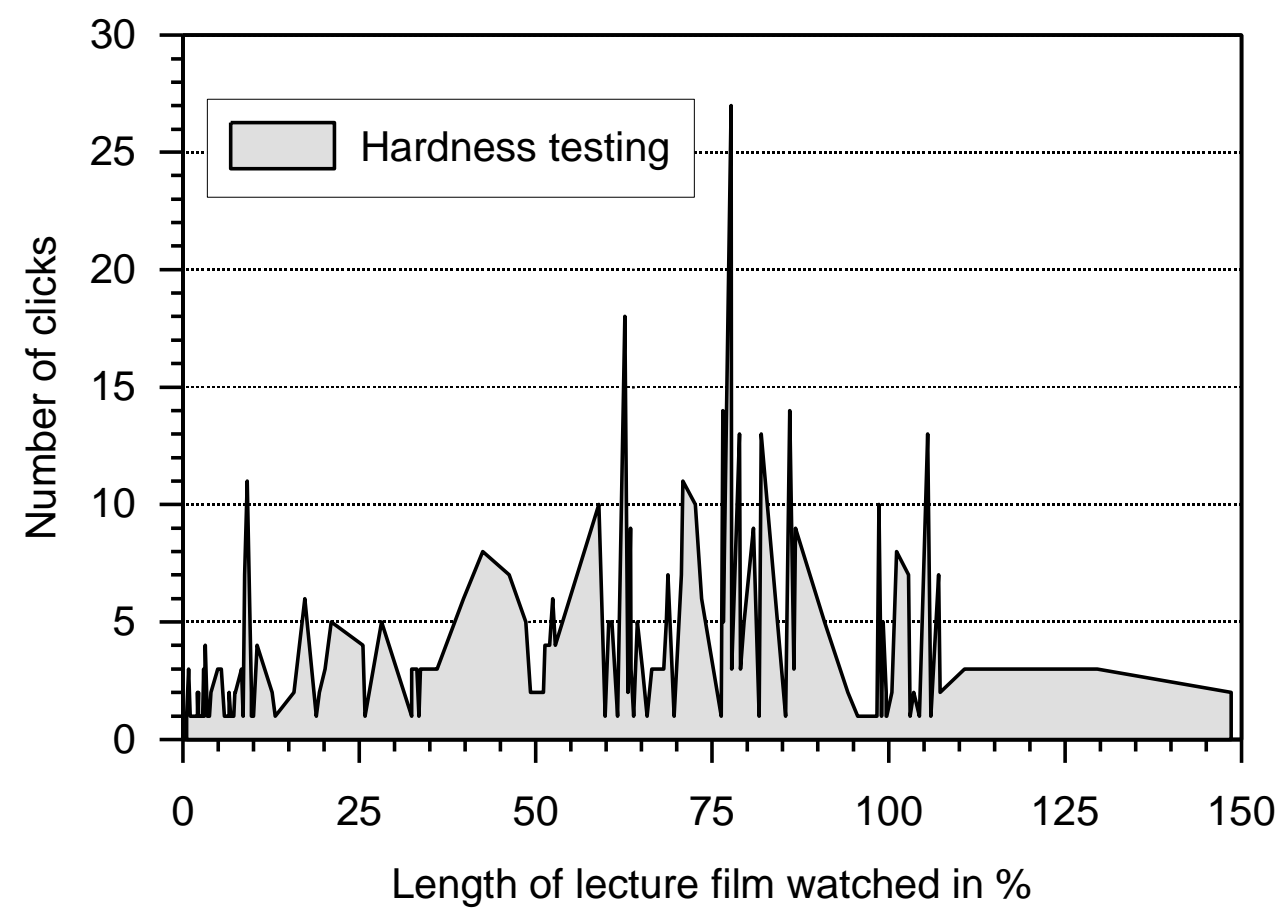

Fig. 4. Number of clicks as a function of the actual length watched in percent of the lecture film "hardness testing. Results exceeding $100 \%$ indicate the film end and titles. Most students watched more than $75 \%$ of the lecture film.

After watching the introductory films more download activity was noticed assumedly accompanied by studying of the lectures that were provided to prepare the experiments. Most students were well prepared for class, e.g. notes and handwritten summaries were brought along, mindmaps and summary sheets were downloaded and memorized. The additional learning material meant to understand the science behind the results they produced in the lab was regarded helpful. Student groups worked homogenously with lots of inspiration. They asked important questions, initiated discussions, were eager to dispose their knowledge and learn more of the details. Even those students, who did not attend the lecture classes increased their understanding of complicated correlations.

Nearly $50 \%$ of the students watched lecture films before the face-to-face laboratory lecture, and preferred films over books or online lectures because the explanation is given directly 
(figure 5). However, more students state that they watched the lecture videos after face-toface time and therefore used the videos for post-processing of the laboratory course content. Approximately $1 / 3$ of the students state that lecture videos give an extra degree of freedom in their learning methods. Lecture videos may be used at any time provided a working internet connection helping students who have to take care of family or work. In general the combination of interactive online lectures, tests and quizzes with the lecture videos provides a highly appreciated learning environment: Pfennig (2018).

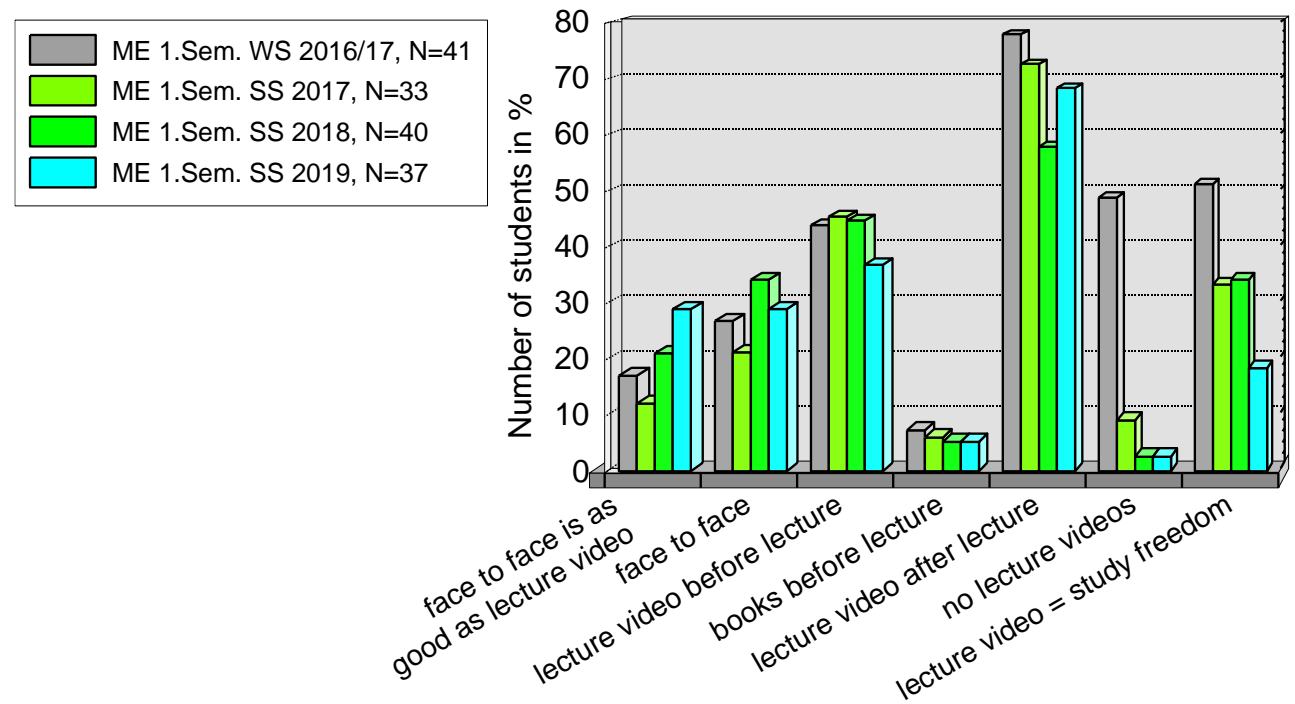

Fig. 5. Preference of lecture materail in first year material science course. (multiple choices were possible)

In general, students achieved lower grades after implementation of lecture videos as means of laboratory preparation. This may be due to the "easy going" attitude towards lecture videos in the first semester. Students may have not taken lecture films as a serious method of preparing, leaving them with the feeling of being experts after watching the difficult content only once. Grades achieved in the laboratory course is directly attributed to the students learning ability and motivation before the course. Even if not all of the lab excercises accounted for better results and the sum of all 5 experiments did not show an improvement of grades there is an increase in students 'attention and individual improvement of pre-lab course test results. Course discussions are encouraged and led with a deeper understanding of the background science. Lecture films are therefore a probate media to encourage students to self-study and prepare for a laboratory course. These films therefore provide excellent requirements in these inverted laboratory classroom scenarios as shown by various authors: Berrett (2012), Pfennig (2016-2), Pfennig (2019-1), Thai (2017). However, it is assumed that students need to learn how to study using lecture videos in the first place to be accounted as 
fully accepted and useful teaching media. It is therefore necessary to guide students how to use lecture films in a higher education context. Lecture films have to be worked with in a similar way as books: take your time, look for explanations of difficuls words or settings and write down and summarize the essentials.

\section{Conclusion}

The peer-to-peer approach of involving students into the implementation of teaching material in an interdisciplinary concept of teaching materials science was successfully chosen to produce lecture videos by guided student project groups. Self studying teaching material was carefully prepared to introduce 5 different materials testing experiments in a practical materials science laboratory course.

In general students rate these introductory videos as beneficial and entertaining because for most of them it is the first time working in a laboratory. After watching the lecture films as means of an inverted classroom learning scenario students knew how to work the equipment and therefore fewer mistakes occurred during the experimental procedures. They were prepared better for the questioning prior to the experiment, got involved into deeper discussions and most of them had taken serious notes improving their learning skills. Data from the course showed enhanced download activity of learning materials after watching the introductory film. However, even with an initial shift of the pre-test results to better grades with the implementation of lecture films starting summer semester 2015, the evaluation over 9 semester does not show a great benefit in terms of students grades. Introductory videos do not automatically enhance the students' learning outcome. Moreover, this is directly attributed to the students learning ability and motivation before the course. Still, the implementation of lecture videos was assessed as beneficial in terms of knowledge upon upcoming laboratory procedures (do-s and don't-s), concentration and attentiveness as well as scientific level of communication during class.

\section{References}

Al-Jandan, B.A., Farooq, I. and Khan, S.Q., Students' perspectives on the relevance of internet-based educational videos in dental education, Journal of Taibah University Medical Sciences (2015) 10(3), 288-292

Ashby, M., Shercliff, H., Cebon, D.: Materials Engineering, Science, Processing and Design, 2013: ISBN-13: 978-0080994345 ( $3^{\text {rd }}$ edition)

Berrett, D.: How 'flipping' the classroom can improve the traditional lecture, The Cronicle of Higher Education (2012)

Colorado State Universtiy, Using Peer Teaching in the Classroom, (2015), http://teaching.colostate.edu/tips/tip.cfm?tipid $=180$ 
Crooka,C., Schofield, L., The video lecture, The Internet and Higher Education 34 (2017) $56-64$

Goto K, \& Schneider, J., Learning through teaching: Challenges and opportunities in facilitating student learning in food science and nutrition by using the interteaching approach. Journal of Food Science Education 9(1) (2010) 31-35.

Gulley, O.D., Jackson, A.L., A case study on using instructor-recorded videos in an upper level economics course, International Review of Economics Education 23 (2016) 28-33

Havergal C., Videoing lectures 'has no impact' on attendance, says study, 2015, https://www.timeshighereducation.com/news/videoing-lectures-has-no-impactattendance-says-study

Kay, R., Kletskin, I., Evaluating the use of problem-based video podcasts to teach mathematics in higher education, Computers \& Education 59 (2012) 619-627

Kon, H., Botelho, M.G., Bridges, S., Chiu Man Leung, K., The impact of complete denture making instructional videos on self-directed learning of clinical skills, journal of prosthodontic research 59 (2015) 144-151

Pfennig, Anja and Hadwiger, Paul, Peer-to-peer lecture films - a successful study concept for a first year laboratory material science course, Procedia - Social and Behavioral Sciences 228 (2016) 24-31

Pfennig, A., Inverting the Classroom in an Introductory Material Science Course, Procedia Social and Behavioral Sciences 228 (2016) 32-38

Pfennig, A., Improvement of learning outcome in material science through inverted classroom techniques and alternative course assessment, JFLET Journal of Foreign Language Education and Technology, 3/1 (2018), 148-162

Pfennig, A., "Making it Work" - Practice Examples of Preparation and Embedding Peer-toPeer Lecture Films in Successful Inverted Classroom Scenarios. PEOPLE: International Journal of Social Sciences, 5/1 (2019) 640-655

Pfennig, A., Lehrfilme einfach einfach machen - erfolgreiche Konzeptionierung von Peer-toPeer Lehrfilmen. In: Pinkwart, N. \& Konert, J. (Hrsg.), DELFI 2019. Bonn: Gesellschaft für Informatik e.V.. (S. 277-282). DOI: 10.18420/delfi2019_98

Rose, E., Claudius, I. Tabatabai, r., Kearl, L., Behar, S., and Jhun, P., The flipped classroom in emergency medicine using online videos with interpolated questions, The Journal of Emergency Medicine, Vol. 51, No. 3 (2016) 284-291

Szpunar, K.K., Jing, H.G., Schacter, D.L., Overcoming overconfidence in learning from video-recorded lectures:Implications of interpolated testing for online education, Journal of Applied Research in Memory and Cognition 3 (2014) 161-164

Thai, N.T.T., De Wever, B., Valcke, M., The impact of a flipped classroom design on learning performance in higher education: Looking for the best "blend" of lectures and guiding questions with feedback, Computers \& Education 107 (2017) 113-126

Ware, M., Peer review: benefits, perceptions and alternatives, Publishing Resear-ching Consortium, www.publishingresearch.net/documents/PRCsummary4Warefinal.pdf 2015 